\title{
COMPREHENSIVE MARKET MICROSTRUCTURE MODEL: CONSIDERING THE INVENTORY HOLDING COSTS
}

\author{
Doojin RYU \\ College of Economics, Sungkyunkwan University, 25-2 Sungkyunkwan-ro, \\ Jongno-gu, Seoul 03063, Republic of Korea \\ E-mail: sharpjin@skku.edu
}

Received 21 March 2016; accepted 20 January 2017

\begin{abstract}
The purpose of this study is to propose a structural market microstructure model and examine the intraday price and spread dynamics in a highly liquid market. We extend the model of Madhavan, Richardson, and Roomans to devise a comprehensive order indicator model that considers the order duration, order size, market liquidity, and most importantly, inventory holding costs. Our empirical analyses on the KOSPI200 futures market indicate that the inventory holding costs of liquidity suppliers explain a significant portion of model-implied spreads. Meanwhile, the duration and size of traded orders convey significant information content on the inventory holding component. Market liquidity is also an important consideration for futures traders who have to manage their inventory holding costs.
\end{abstract}

Keywords: bid-ask spreads, intraday trading, inventory holding cost, KOSPI200 futures, market microstructure, order indicator model.

JEL Classifications: G10, G15.

\section{Introduction}

We develop a comprehensive market microstructure model that considers various aspects of microstructure events to examine the intraday price dynamics and components of bid-ask spreads. Since the advent of classical theories on market microstructure, such as those presented by Glosten and Milgrom (1985), Kyle (1985), and Easley and O'Hara (1987), financial economists have developed structural models to examine the microstructure issues of global financial markets and estimate the components of bidask spreads using high-frequency intraday datasets ${ }^{1}$. Earlier studies by Roll (1984), Choi et al. (1988), and Stoll (1989) attempt to measure the spreads and their components based on the covariance of actual market prices, which contain insufficient information on the intraday price dynamics. Following structural models use the information on the intraday dynamics of order indicators, and thus they are classified as order in-

\footnotetext{
${ }^{1}$ For a detailed review on financial market microstructure research and structural models in this field, refer to the surveys presented by Madhavan (2000) and Biais et al. (2005).
} 
dicator models. The order indicator model of Glosten and Harris (1988, hereafter the GH model), also called the primitive structural model, systematically and successfully decomposes the spreads into the permanent and temporary components derived from informed trading and uninformed trading, respectively. Huang and Stoll (1997, hereafter the HS model) and Madhavan, Richardson, and Roomans (1997, hereafter the MRR model) extend the GH model by considering the serial correlation of the order indicator, and they model various aspects of bid-ask spreads.

Though the HS and MRR models are regarded as breakthrough structural models, they are based on some unrealistic assumptions. These models assume that all traded orders have the same interval and all investors submit orders of the same size. To overcome the limitations of these models, recent studies propose using extended structural models by modifying the framework of the MRR model, which is robust, flexible, and easily extended. Angelidis and Benos (2009), Ahn et al. (2010), and Ryu (2013a) independently extend the MRR model to successfully capture the size effects of incoming orders. They find that large orders usually cause a greater permanent price impact than smaller orders, and interpret this result as evidence of the information superiority of large traders.

Another strand of the literature considers the informative role of the duration between two consecutive traded orders (i.e., inter-transaction times) in explaining the intraday price discovery process ${ }^{2}$. Previous financial econometric research argues the order duration itself contains information content (Spierdijk 2004; Xu et al. 2006; Furfine 2007; Chen et al. 2008; Liu, Maheu 2012). Motivated by such studies, Grammig et al. (2011) and Ryu (2015b) devise extended MRR models, which exploit the information of order duration when estimating the spread components. Though they provide opposite views on whether faster trading (i.e., shorter order duration) increases the permanent price impact, which is a proxy for informed trading, both studies conclude that duration holds significant information content.

Most recently, Chung et al. (2016) and Ryu (2016) also exploit the MRR framework to develop advanced structural models that consider market depth when examining the intraday price formation and spread components. Most previous structural microstructure models do not consider the current level of market liquidity that all investors face when deciding to submit their orders. Given that liquidity is one of the most important considerations for investors, who need to decide "when and to what extent" to submit orders, the consideration of the liquidity effect provides additional implications.

Though the advanced models attempt to construct a complete structural model framework that incorporates the order duration, size, and market liquidity, they still suffer from a weakness in that they do not consider the inventory holding costs of liquidity suppliers. One of the most important reasons to ignore the inventory holding costs in the recent empirical microstructure models is that they analyze the intraday price dynamics and bid-ask spread components of purely order-driven markets where there is no

\footnotetext{
2 The duration and inter-transaction times are used interchangeably in the previous literature (Chung et al. 2016; Ryu 2015b, 2016). We use the order duration to maintain consistency in this study. Since we analyze only the traded orders from among all submitted orders, in this study, the term "orders" actually indicates traded orders only.
} 
designated market maker. The recent models assume that investors are not sensitive to their inventory levels. However, as claimed by Ahn et al. (2002) and Hagströmer et al. (2016), even in the order-driven markets, limit order traders play the role of liquidity suppliers, and their trading generates explicitly positive bid-ask spreads. These liquidity suppliers can regard their inventory levels and holding costs as significant when deciding to submit orders. Therefore, changes in price and spread components caused by inventory holding costs should be considered to obtain further insight into the intraday price behavior and dynamics of financial markets.

Motivated by these limitations of the previous approaches, we suggest a further extended microstructure model that captures the effects of the order duration, size, and market liquidity, and most importantly, the inventory holding costs of liquidity suppliers. Our empirical analyses indicate that the inventory holding costs explain a significant portion of bid-ask spreads and affect intraday price dynamics even in a highly liquid KOSPI200 futures market where $i$ ) there is no designated market maker and $i$ ) investors can trade with less market friction and fewer trading constraints. Though the KOSPI200 futures traders might feel relatively less pressure with regard to their inventory levels and holding costs, our empirical results suggest the existence of the significant inventory holding component in the futures market. Further, after controlling for the inventory holding costs, we find that other market considerations such as the order duration, size, and market liquidity also play significant roles in explaining the intraday price dynamics and bid-ask spread components, which justifies the comprehensiveness of our microstructure model. Lastly, the information effects of order duration and size on the inventory holding component are significantly related to futures market variables such as the trading environment, asset price, liquidity level, volatility, and intraday time periods.

\section{KOSPI200 futures market}

The KOSPI200 futures market is one of the world's most liquid index futures markets. Supported by the synergistic effect of simultaneous trading with the KOSPI200 index options, which also exhibit top-tier liquidity levels on a global scale, the trading volume of the KOSPI200 futures has continuously increased since it commenced trading in 1996. ${ }^{3}$ The high liquidity of the futures market results in little market friction and lower transaction cost for futures trading, which enables us to measure the net price effect of traded orders more accurately and with less bias ${ }^{4}$. In addition to the high liquidity, a balanced investor participation rate is also an important trait of the futures market, which suggests that various types of futures traders supply and provide the market liquidity

\footnotetext{
${ }^{3}$ For the relationship between the KOSPI200 futures and options markets and the characteristics and general descriptions of the Korea's index derivatives markets, refer to Ryu (2015a), Lee et al. (2015), Ryu et al. (2015), Lee and Ryu (2016), Song et al. (2016), Sim et al. (2016), and Yang et al. (2017).

${ }^{4}$ Investors involved in equity trading in the Korean stock market are required to pay various fees such as brokerage, member, and exchange fees. Stock traders are also required to pay a government tax for capital gains. In contrast, most KOSPI200 futures traders are exempt from fees and taxes, which dramatically reduces the transaction costs of futures trading and induces higher market participation by liquidity traders. This trading environment of the KOSPI200 futures market indicates that futures trading entails significantly less market friction and lower transaction costs than equity trading.
} 
(Han et al. 2015; Kim, Ryu 2015; Kim et al. 2015; Webb et al. 2016; Ryu, Yang 2017). Table 1 shows the trading volume of the futures market, which is the proxy for the market liquidity. The table presents the trading activities of the KOSPI200 futures traders, based on the information from the Korea Exchange (KRX). It presents the number of futures contracts traded (in contracts and percentage values) by four investor groups, namely, domestic individuals, domestic money managers, domestic banks, and foreigners, for the sample period from January 2003 to September 2006.

Table 1. Trading volume of the KOSPI200 futures

\begin{tabular}{lcc}
\hline & In contracts & Proportions \\
\hline Domestic individuals & $191,312,649$ & $48.87 \%$ \\
\hline Domestic money managers & $115,776,044$ & $29.58 \%$ \\
\hline Domestic banks & $4,770,291$ & $1.22 \%$ \\
\hline Foreign investors & $79,600,220$ & $20.33 \%$ \\
\hline Total & $391,459,204$ & $100 \%$ \\
\hline
\end{tabular}

Note: Korea Exchange (KRX; www.krx.co.kr).

The structure of the KOSPI200 futures market is an additional reason for us to focus on the futures market. The index futures market does not impose any short-sale constraint impeding the price adjustment in response to the information conveyed by sell orders. The market structure also enables investor anonymity. There is no upstairs market for large traders, most of whom are informative institutional investors, and liquidity suppliers cannot identify their counterparties. All orders submitted by futures traders are automatically transacted by the centralized electronic limit order book, which enables the anonymity of all market participants and enhances market transparency. Therefore, each trader decides to submit either aggressive orders that demand and consume liquidity, or passive orders that supply and provide liquidity, by considering their information and inventory levels rather than the trading irregularities, market friction, and leakage of their trading strategies. This trading environment of the futures market helps our structural models to identify the inventory holding component without biases.

\section{Sample data}

We analyze the intraday TAQ (Trade and Quote) dataset of the KOSPI200 futures from April 2003 to September 2006. On a normal trading day, the index futures market opens at 8:00 and closes at 15:15. We exclude the call-auction trading sessions (15:05-15:15) from our sample and only analyze trades and quotes recorded during the continuous trading session (9:00-15:05), where all orders are immediately traded or consolidated into the limit order book based on the degree of their order aggressiveness. We also exclude from the sample several trading days when the trading session operates differently ${ }^{5}$.

\footnotetext{
${ }^{5}$ Since this proportion is very small, the exclusion does not affect our results.
} 
Our dataset provides detailed and accurate information on transaction prices, quantities, quoted bid-ask spreads, market depth, transaction time, and trade directions. An important advantage of the dataset is that it includes the exact and detail classification of the trade direction, which enables us to reliably estimate the order indicator models.

On each trading day, four different futures contracts with different maturity periods are traded on the KRX. Since only the nearest maturity futures contracts are actively traded, we limit our analysis to the nearest maturity contracts and ignore the longer term contracts. To eliminate the possible effect of maturity biases on the model estimation, we construct 14 futures series, each covering a three-month period. For example, the first futures series (Series 1) ranges from April to June of 2003, and the last futures series (Series 14) ranges from June to September of 2006. The quoting unit of the KOSPI200 futures market is the "point," and we present the estimated model parameters in terms of both the points and the percentages of futures prices.

Table 2 presents the basic summary statistics of our sample data with respect to the 14 futures series used for model estimation. For each futures series, the table presents the daily average values of size-weighted average transaction price (Price), duration between two consecutive traded orders (Duration), order sizes (Size), and market depth (Depth). The prices are measured in points, and the durations are measured in seconds. The sizes and depth are measured in contracts. The time trend of futures prices (Price) generally exhibits an increasing pattern. The average price of the first futures series (Futures 1) is 74.63 , and it increases to 174.61 at the last futures series (Futures 14), reflecting the market optimism for our sample period. However, other proxies for liquidity and/or trading intensity (i.e., Duration, Size, and Depth), which are used for the model estimation, do not exhibit a specific pattern.

Table 2. Summary statistics of the KOSPI200 futures market variables

\begin{tabular}{lcccc}
\hline & Price & Duration & Size & Depth \\
\hline Futures 1 & 74.63 & 0.771 & 9.04 & 2869.5 \\
\hline Futures 2 & 78.06 & 0.851 & 10.38 & 3414.9 \\
\hline Futures 3 & 93.22 & 1.174 & 11.11 & 3952.3 \\
\hline Futures 4 & 101.02 & 0.954 & 10.37 & 2919.2 \\
\hline Futures 5 & 113.46 & 1.236 & 10.43 & 2987.9 \\
\hline Futures 6 & 105.47 & 0.716 & 8.33 & 1762.3 \\
\hline Futures 7 & 99.81 & 0.816 & 7.97 & 2364.6 \\
\hline Futures 8 & 110.72 & 0.875 & 8.18 & 2228.8 \\
\hline Futures 9 & 123.43 & 1.023 & 7.93 & 2241.6 \\
\hline Futures 10 & 123.77 & 1.063 & 7.48 & 2120.5 \\
\hline Futures 11 & 144.09 & 0.918 & 7.22 & 1585.9 \\
\hline Futures 12 & 160.97 & 0.818 & 6.53 & 1186.0 \\
\hline Futures 13 & 174.29 & 0.684 & 6.22 & 1086.1 \\
\hline Futures 14 & 174.61 & 0.704 & 6.12 & 1120.3 \\
\hline Average & 123.23 & 0.893 & 8.25 & 2214.6 \\
\hline
\end{tabular}




\section{Basic structural model}

Our comprehensive market microstructure model is based on the flexible framework of the MRR model. In the framework, all incoming traded orders exert an influence on intraday asset price formations, and contribute to explicitly positive bid-ask spreads. In contrast to the MRR model, which ignores the inventory holding costs and liquidity suppliers, our model illustrates the causes of positive bid-ask spreads based on three components: informed trading (the permanent impact component), inventory holding costs of liquidity suppliers (the inventory holding component), and other order handling costs of traders (the order processing component). We derive a basic structural model first, which considers all three components, but maintains the same assumptions on order size and duration (i.e., the unit size and duration). Equation (1) explains that the post-trade fundamental asset value $\left(\mu_{t}\right)$ changes owing to the unexpected portion of incoming trades $\left(x_{t}-E\left[x_{t} \mid x_{t-1}\right]\right)$ and updates to public information shock $\left(\varepsilon_{t}\right)$. Equation (2) shows that the actual transaction price $\left(P_{t}\right)$ dynamics is affected by the asset value $\left(\mu_{t}\right)$, order processing issue of the incoming trade $\left(\beta x_{t}\right)$, inventory level of the liquidity supplier $\left(\delta \sum_{i=1}^{t}\left\{x_{i}\right\}\right)$ accumulated since the commencement of the initial trade (i.e., $\left.x_{1}\right)$, and rounding error term $\left(\xi_{t}\right)$. Equation (3) shows that the bid-ask mid-quote price $\left(m_{t}\right)$ reflects not only the fundamental value, but also the inventory holding costs of liquidity suppliers:

$$
\begin{gathered}
\Delta \mu_{t}=\mu_{t}-\mu_{t-1}=\alpha\left(x_{t}-E\left[x_{t} \mid x_{t-1}\right]\right)+\varepsilon_{t}, \text { where } E\left[x_{t} \mid x_{t-1}\right]=\rho x_{t-1}, \\
P_{t}=\mu_{t}+\beta x_{t}+\delta \sum_{i=1}^{t}\left\{x_{i}\right\}+\xi_{t}, \text { and } \\
m_{t}=\mu_{t}+\delta \sum_{i=1}^{t}\left\{x_{i}\right\} .
\end{gathered}
$$

In the above Equations (1-3), the subscripts $i$ and $t$ indicate the $i^{\text {th }}$ and $t^{\text {th }}$ orders, respectively. $x_{t}$ denotes an order indicator variable, which equals $1(-1)$ for buyer-initiated (seller-initiated) trades. $\rho$ is the serial correlation of the order indicator variable. $\alpha, \beta$, and $\delta$ measure the permanent price impact owing to informed trading, temporary price effect related to order processing costs, and inventory holding costs of liquidity suppliers, respectively. Combining these three equations, we derive the following moment Equations (4) and (5), to carry out the generalized method of moments (GMM) estimation, which is free from distributional assumptions and robust to heteroskedasticity and serial correlation found in the error term $\left(v_{t}\right)$ in Equation (4). The equations for the GMM estimation are presented in equation (6) where $v_{0}$ and $u_{0}$ denote constant drift terms.

$$
\begin{gathered}
\Delta P_{t}=P_{t}-P_{t-1}=(\alpha+\beta+\delta) x_{t}-(\rho \alpha+\beta) x_{t-1}+v_{t}, \text { where } v_{t}=\varepsilon_{t}+\xi_{t}-\xi_{t-1}, \\
\Delta m_{t}=m_{t}-m_{t-1}=(\alpha+\delta) x_{t}-\rho \alpha x_{t-1}+u_{t} \text {, and }
\end{gathered}
$$




$$
E\left[\begin{array}{c}
x_{t-1}\left(x_{t}-\rho x_{t-1}\right) \\
\mathrm{v}_{t}-\mathrm{v}_{0} \\
x_{t}\left(\mathrm{v}_{t}-\mathrm{v}_{0}\right) \\
x_{t-1}\left(\mathrm{v}_{t}-\mathrm{v}_{0}\right) \\
u_{t}-u_{0} \\
x_{t}\left(u_{t}-u_{0}\right) \\
x_{t-1}\left(u_{t}-u_{0}\right)
\end{array}\right]=0 .
$$

Table 3 presents the estimated results of the basic model. For each futures series, the table shows the parameter estimates $(\alpha, \beta, \delta$, and $\rho)$, as well as the model-implied percentage spread (Spread) and its component measures (Perm, Ord, and Inv). $\alpha, \beta$, and $\delta$ denote the permanent impact, order processing component, and inventory holding component parameters, respectively. The $t$-statistic of each parameter estimate is shown in parentheses. Perm, Ord, Inv, and Spread denote the permanent impact component (percentage $\alpha$ ), order processing component (percentage $\beta$ ), inventory holding component (percentage $\delta$ ) and model-implied spread $(2 \times($ Perm + Ord $+I n v))$, respectively. These components are shown as the percentage values of the underlying futures prices.

Table 3. Estimation of the basic structural model

\begin{tabular}{|c|c|c|c|c|c|c|c|c|c|c|c|c|}
\hline & & A & & $\beta$ & & $\delta$ & & $\rho$ & Perm & Ord & Inv & Spread \\
\hline & Coe & f. $\times 100$ & $\mathrm{Coe}$ & $f . \times 100$ & Coe & $f . \times 100$ & & oef. & Est. $\times 100$ & Est. $\times 100$ & Est. $\times 100$ & Est. $\times 100$ \\
\hline Futures 1 & -0.457 & $(-149.9)$ & 2.465 & (1682.0) & 0.249 & (133.7) & 0.551 & (351.3) & -0.585 & 3.158 & 0.318 & 5.78 \\
\hline Futures 2 & -0.432 & $(-117.9)$ & 2.457 & (1397.5) & 0.192 & (109.7) & 0.627 & (354.1) & -0.463 & 2.636 & 0.205 & 4.76 \\
\hline Futures 3 & -0.563 & $(-164.6)$ & 2.450 & (1328.3) & 0.297 & (144.7) & 0.552 & $(367.7)$ & -0.558 & 2.425 & 0.294 & 4.32 \\
\hline Futures 4 & -0.593 & $(-141.0)$ & 2.443 & (1305.5) & 0.311 & (123.9) & 0.559 & (324.3) & -0.523 & 2.153 & 0.274 & 3.81 \\
\hline Futures 5 & -0.832 & $(-204.4)$ & 2.446 & (1308.5) & 0.550 & $(166.2)$ & 0.458 & (336.3) & -0.789 & 2.319 & 0.522 & 4.10 \\
\hline Futures 6 & -0.610 & $(-182.6)$ & 2.446 & $(1408.2)$ & 0.328 & (160.8) & 0.548 & (384.7) & -0.611 & 2.451 & 0.329 & 4.34 \\
\hline Futures 7 & -0.651 & $(-185.9)$ & 2.457 & (1280.4) & 0.355 & (160.9) & 0.547 & (392.6) & -0.588 & 2.219 & 0.321 & 3.90 \\
\hline Futures 8 & -0.664 & $(-166.1)$ & 2.440 & (932.0) & 0.339 & (148.8) & 0.575 & $(376.2)$ & -0.538 & 1.977 & 0.274 & 3.43 \\
\hline Futures 9 & -0.639 & $(-161.7)$ & 2.427 & $(816.5)$ & 0.323 & $(145.1)$ & 0.586 & $(365.2)$ & -0.517 & 1.961 & 0.261 & 3.41 \\
\hline Futures 10 & -0.792 & $(-200.4)$ & 2.414 & (893.8) & 0.435 & (167.8) & 0.543 & (384.7) & -0.549 & 1.675 & 0.302 & 2.85 \\
\hline Futures 11 & -0.961 & $(-220.6)$ & 2.405 & (1011.6) & 0.616 & (179.0) & 0.470 & (347.4) & -0.597 & 1.494 & 0.382 & 2.56 \\
\hline Futures 12 & -1.020 & $(-230.4)$ & 2.384 & (1254.0) & 0.694 & (186.8) & 0.439 & $(351.5)$ & -0.585 & 1.368 & 0.398 & 2.36 \\
\hline Futures 13 & -0.976 & $(-226.4)$ & 2.390 & (1271.1) & 0.655 & (187.8) & 0.441 & $(359.0)$ & -0.559 & 1.369 & 0.375 & 2.37 \\
\hline Futures 14 & -0.848 & $(-210.8)$ & 2.387 & $(1254.7)$ & 0.532 & (181.0) & 0.471 & $(372.5)$ & -0.496 & 1.396 & 0.311 & 2.42 \\
\hline Average & -0.717 & $(-183.1)$ & 2.429 & (1224.6) & 0.420 & (156.9) & 0.526 & $(362.0)$ & -0.568 & 2.043 & 0.326 & 3.60 \\
\hline
\end{tabular}

Note: Coef., Est., and Average represent the coefficients, estimates, and average value, respectively. 
All coefficient estimates are highly significant, indicating that our model specification is appropriate. The order processing component $(\mathrm{Ord})$ constitutes the largest proportion of the model-implied spread and causes the highest price change (on average, 0.02429 point or $0.02043 \%$ of the futures prices), which reflects the high liquidity and low market friction of the KOSPI200 futures market. The relatively greater proportion of Ord estimates in forming the spread also indicates that liquidity and uninformed trades are predominant in the futures market.

In contrast, the permanent impact component (Perm) has negative values in all futures series. This result seems to be somewhat counterintuitive considering that informed trading usually causes positive and permanent changes in asset prices and that the previous studies decomposing the spread only into two parts (the permanent and temporary components) consistently report positive estimates for this component (Ahn et al. 2008, 2010; Ryu 2011, 2013a, 2013b). However, the negative estimate of Perm is also a universal phenomenon shared by the structural order indicator models that explicitly conceptualize the inventory holding component. For example, Huang and Stoll (1997) analyze the trade and quote (TAQ) dataset of the New York Stock Exchange (NYSE) and report negative permanent impact estimates through their HS model ${ }^{6}$. The followings are two possible interpretations for the negative estimates. First, in an extremely highly liquid market with keenly interested global investors, such as the KOSPI200 futures market, the explanatory power of informed trading on the intraday price and spread dynamics is much smaller than that of uninformed and liquidity trading. Second, for the futures traders who decide to submit orders in the KOSPI200 futures market, inventory holding costs, which can be controlled by the will of traders, become a more important consideration than the short-term profit-seeking strategies based on their imperfect information superiority. Therefore, after explicitly incorporating the inventory holding component into the structural model, the inventory holding issue may diminish the explanatory power of the permanent impact component.

The inventory holding component estimates (Inv), which we are primarily interested in, are highly and positively significant for all futures series, constitute a substantial portion of the model-implied spread, and explain intraday price changes significantly. On average, Inv causes the futures price to change by 0.00420 point or $0.00326 \%$, and explains approximately $18 \%{ }^{7}$ of the spread. This result indicates that considering inventory holding cost is important even in the KOSPI200 futures market, which is a purely order-driven market without designated market makers. It also supports the role of liquidity suppliers in forming the spread. Their transactions significantly affect the intraday price dynamics in the KOSPI200 futures market.

\footnotetext{
${ }^{6}$ Though they obtain some positive estimates in their artificially bunched dataset, the data processing procedure is arbitrary. In the original dataset, the HS model reports significantly negative estimates for the permanent impact component.

${ }^{7}$ This figure is calculated using the following formula: $100 \times \operatorname{Inv} /(\operatorname{Perm}+\operatorname{Ord}+\operatorname{Inv})$.
} 


\section{Extended structural model}

Though our basic model successfully decomposes the spread and supports the existence of the inventory holding costs of liquidity suppliers, it does not consider the various market microstructure factors, which results in the loss of valuable information while examining the intraday price dynamics. In this section, we extend the basic model by incorporating the $i$ ) inter-transaction times between orders (i.e., order duration), $i i$ ) trading volume (i.e., order size), and iii) liquidity (i.e., current market depth) into the structural model. The recent studies reviewed in the section titled Introduction show that all these microstructure factors convey significant information and are important considerations for investors who make strategic order submissions. For example, shorter order durations reflect the dominance of aggressive orders and/or the prevalence of ordersplitting strategies (Kim, Ryu 2012; Ryu 2012), whereas longer trade durations reflect the prevalence of passive order submissions and cause the market to slow down (Chung et al. 2016). Futures traders may decide to submit large orders to maximize their profit before their information superiority disappears. Alternatively, they may submit smaller orders to camouflage their identity and reduce the adverse price impact in a relatively less liquid market situation. The market depth is the most direct and appropriate proxy to measure the current status of market liquidity in the highly liquid market.

In the extended framework, Equation (7) explains that the unexpected portion of incoming trades $\left(x_{t}-E\left[x_{t} \mid x_{t-1}\right]\right)$ affects the change in asset value $\left(\Delta \mu_{t}\right)$ in four ways: the constant portion captured by $\alpha_{0}$, the duration-related portion captured by $\alpha_{1}$, the sizerelated portion captured by $\alpha_{2}$, and the liquidity-related portion captured by $\alpha_{3}$ :

$$
\begin{aligned}
& \Delta \mu_{t}=\mu_{t}-\mu_{t-1}=\left(\alpha_{0}+\alpha_{1} \ln \left(D_{t}\right)+\alpha_{2} \sqrt{ } S_{t}+\alpha_{3} L_{t}\right)\left(x_{t}-E\left[x_{t} \mid x_{t-1}\right]\right)+\varepsilon_{t}, \\
& \text { where } E\left[x_{t} \mid x_{t-1}\right]=\rho x_{t-1} .
\end{aligned}
$$

In Equation (7), $D_{t}$ denotes the inter-transaction time (i.e., order duration) between the $t-1^{\text {th }}$ and $t^{\text {th }}$ orders. $S_{t}$ denotes the size (i.e., volume) of an incoming order at time $t$. $L_{t}$ implies market liquidity, which is measured by the square root of the market depth quoted immediately before the futures traders submit the $t^{\text {th }}$ orders. The market depth is calculated as the sum of all standing orders at the first, second, third, fourth, and fifth bid and ask quotes. The term $\alpha_{0}+\alpha_{1} \ln \left(D_{t}\right)+\alpha_{2} \sqrt{ } S_{t}+\alpha_{3} L_{t}$ measures the permanent price impact of the $t^{\text {th }}$ order.

Equation (8) shows how the transaction price $\left(P_{t}\right)$ is determined by the extended framework. As in the basic model, the fundamental value, temporary order processing component $\left(\beta_{0}+\beta_{1} \ln \left(D_{t}\right)+\beta_{2} \sqrt{ } S_{t}+\beta_{3} L_{t}\right)$, inventory holding component $\left(\delta_{0}+\delta_{1} \ln \left(D_{t}\right)+\right.$ $\left.\delta_{2} \sqrt{ } S_{t}+\delta_{3} L_{t}\right)$, and rounding error $\left(\xi_{t}\right)$ determine the transaction price. The critical differences are that we consider the order duration, order size, and market depth when measuring the effects of order processing and inventory holding costs, and that the inventory level is affected by the actual order sizes $\left(S_{i}\right)$.

$$
\begin{aligned}
& P_{t}=\mu_{t}+\left(\beta_{0}+\beta_{1} \ln \left(D_{t}\right)+\beta_{2} \sqrt{ } S_{t}+\beta_{3} L_{t}\right) x_{t}+ \\
& \left(\delta_{0}+\delta_{1} \ln \left(D_{t}\right)+\delta_{2} \sqrt{ } S_{t}+\delta_{3} L_{t}\right) \sum_{i=1}^{t}\left\{x_{i} \sqrt{ } S_{i}\right\}+\xi_{t},
\end{aligned}
$$


where $\beta_{0}$ and $\delta_{0}$ are constants, $\beta_{1}$ and $\delta_{1}$ capture the duration-related portion, $\beta_{2}$ and $\delta_{2}$ capture the size-related portion, and $\beta_{3}$ and $\delta_{3}$ capture the depth-related portion. Combining Equations (7) and (8), we construct moment Equation (9) for the GMM estimation $^{8}$. The GMM equation of the extended model is shown in Equation (10).

$$
\begin{aligned}
& \Delta P_{t}=P_{t}-P_{t-1}=\left(\alpha_{0}+\beta_{0}\right) x_{t}-\left(\rho \alpha_{0}+\beta_{0}\right) x_{t-1}+\left(\alpha_{1}+\beta_{1}\right) x_{t} \ln \left(D_{t}\right)- \\
& \beta_{1} x_{t-1} \ln \left(D_{t-1}\right)-\rho \alpha_{1} x_{t-1} \ln \left(D_{t}\right)+\left(\alpha_{2}+\beta_{2}+\delta_{0}\right) x_{t} \sqrt{ } S_{t}-\beta_{2} x_{t-1} \sqrt{ } S_{t-1}- \\
& \rho \alpha_{2} x_{t-1} \sqrt{ } S_{t}+\left(\alpha_{3}+\beta_{3}\right) x_{t} L_{t}-\beta_{3} x_{t-1} L_{t-1}-\rho \alpha_{3} x_{t-1} L_{t}+\delta_{1} x_{t} \ln \left(D_{t}\right) \sqrt{ } S_{t}+ \\
& \delta_{2} x_{t} S_{t}+\delta_{3} x_{t} \sqrt{ } S_{t} L_{t}+v_{t}, \text { where } v_{t}=\varepsilon_{t}+\xi_{t}-\xi_{t-1} .
\end{aligned}
$$

$$
\left[\begin{array}{l}
x_{t-1}\left(x_{t}-\rho x_{t-1}\right) \\
\left(\mathrm{v}_{t}-\mathrm{v}_{0}\right) \\
x_{t}\left(\mathrm{v}_{t}-\mathrm{v}_{0}\right) \\
x_{t-1}\left(\mathrm{v}_{t}-\mathrm{v}_{0}\right) \\
x_{t} \ln \left(D_{t}\right)\left(\mathrm{v}_{t}-\mathrm{v}_{0}\right) \\
x_{t-1} \ln \left(D_{t-1}\right)\left(\mathrm{v}_{t}-\mathrm{v}_{0}\right) \\
x_{t-1} \ln \left(D_{t}\right)\left(\mathrm{v}_{t}-\mathrm{v}_{0}\right) \\
x_{t} \sqrt{S_{t}}\left(\mathrm{v}_{t}-\mathrm{v}_{0}\right) \\
x_{t-1} \sqrt{S_{t-1}}\left(\mathrm{v}_{t}-\mathrm{v}_{0}\right) \\
x_{t-1} \sqrt{S_{t}}\left(\mathrm{v}_{t}-\mathrm{v}_{0}\right) \\
x_{t} L_{t}\left(\mathrm{v}_{t}-\mathrm{v}_{0}\right) \\
x_{t-1} L_{t-1}\left(\mathrm{v}_{t}-\mathrm{v}_{0}\right) \\
x_{t-1} L_{t}\left(\mathrm{v}_{t}-\mathrm{v}_{0}\right) \\
x_{t} \ln \left(D_{t}\right) \sqrt{S_{t}}\left(\mathrm{v}_{t}-\mathrm{v}_{0}\right) \\
x_{t} S_{t}\left(\mathrm{v}_{t}-\mathrm{v}_{0}\right) \\
x_{t} \sqrt{S_{t}} L_{t}\left(\mathrm{v}_{t}-\mathrm{v}_{0}\right)
\end{array}\right]=0
$$

Table 4 shows the estimated results of the extended model. The table reports the 13 parameter estimates $\left(\alpha_{0}, \alpha_{1}, \alpha_{2}, \alpha_{3}, \beta_{0}, \beta_{1}, \beta_{2}, \beta_{3}, \delta_{0}, \delta_{1}, \delta_{2}, \delta_{3}\right.$, and $\left.\rho\right)$, the model-implied percentage spread (Spread), and its component measures (Perm, Ord, and Inv). For each futures series, Panel A of Table 4 shows the four permanent-impact-related estimates (the constant parameter $\alpha_{0}$, time-related parameter $\alpha_{1}$, volume-related parameter $\alpha_{2}$,

\footnotetext{
${ }^{8}$ As in the basic model, we can further construct the moment equation for the quoted price change. However, the implications and conclusions with and without the equation are similar.
} 
and depth-related parameter $\alpha_{3}$ ) and the four order-processing-cost-related estimates $\left(\beta_{0}, \beta_{1}, \beta_{2}\right.$, and $\left.\beta_{3}\right)$ of the extended model. The $t$-statistic of each parameter estimate is shown in parentheses. Panel B of Table 4 shows the four inventory holding cost-related estimates $\left(\delta_{0}, \delta_{1}, \delta_{2}\right.$, and $\left.\delta_{3}\right)$ and the serial correlation parameter $(\rho)$. Perm, Ord, Inv, and Spread represent the permanent impact component $\left(\alpha_{0}+\alpha_{1} \ln \left(D_{t}\right)+\alpha_{2} \sqrt{ } S_{t}+\alpha_{3} L_{t}\right)$, order processing component $\left(\beta_{0}+\beta_{1} \ln \left(D_{t}\right)+\beta_{2} \sqrt{ } S_{t}+\beta_{3} L_{t}\right)$, inventory holding component $\left(\delta_{0}+\delta_{1} \ln \left(D_{t}\right)+\delta_{2} \sqrt{ } S_{t}+\delta_{3} L_{t}\right)$, and model-implied spread $(2 \times($ Perm + Ord $+\operatorname{Inv}))$, respectively. These components are shown as the percentage values of the underlying futures prices.

The highly significant and reasonable estimates indicate that our model extension has an economic implication and significance. In the extended framework that considers the various microstructure factors, the order processing component $(\mathrm{Ord})$ is still the largest spread component and causes the highest intraday price change (on average, $0.01832 \%$ of the futures prices) among the three spread components. Consistent with the results found in the basic model, the extended model yields negative permanent impact component values (see Perm).

In the extended model, the inventory holding component (Inv) still plays a significant role in explaining the intraday price dynamics, which means that the inventory holding cost maintains explanatory powers as the spread component even after controlling for information and liquidity effects and considering order characteristics. On average, it causes the futures price to change by $0.00082 \%$ and explains about $4.98 \%{ }^{9}$ of the spread. Most of the inventory holding-related parameters $\left(\delta_{0}, \delta_{1}, \delta_{2}\right.$, and $\left.\delta_{3}\right)$ are significantly estimated. In particular, the estimates for $\delta_{2}$, which capture the size effect, are highly significant in all futures series. This reflects that the inventory holding levels and costs have a direct influence on investors' decisions regarding their order size.

Each of estimated parameters of the extended model provides economic implications for the trading activity and microstructure of the KOSPI200 futures market. Significantly negative $\alpha_{1}$ estimates, which are consistent with the results of Ryu (2015b), support the fact that fast trading indicates informed trading. This reflects the characteristics of informed trading in the index futures market, which include the fast and sophisticated information processing skills and knowledge in response to public news and announcements. Significantly positive $\alpha_{2}$ estimates imply that larger orders are usually more informative than smaller orders, which also reflects the ample liquidity of the futures market. Investors can easily sneak into high liquidity and/or submit large orders without being affected by significant adverse price movements under the highly liquid market condition. Thus, they have little incentive to fragment their orders. They decide to submit large orders if they are confident about their information or expectation to increase their trading profits (Ahn et al. 2010; Ryu 2013a).

\footnotetext{
${ }^{9}$ This figure is calculated using the following formula: $100 \times 0.082 /(-0.265+1.832+0.082)$.
} 


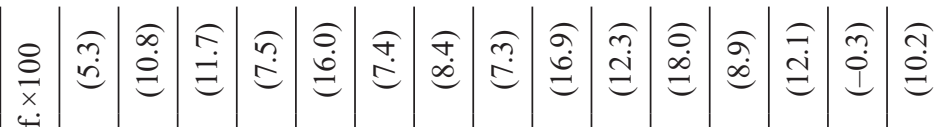

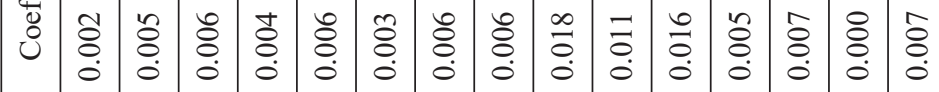

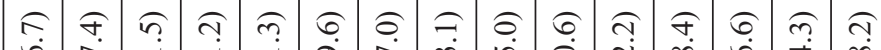
\&

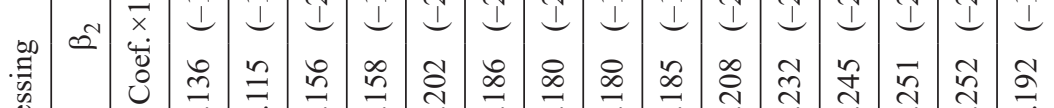

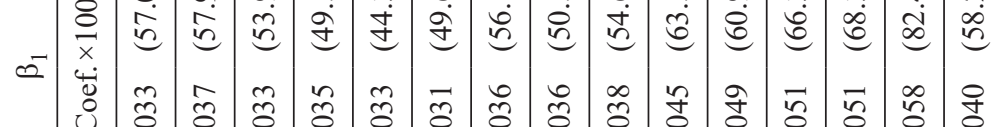

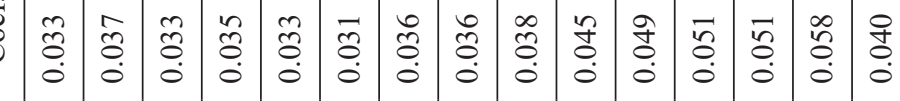

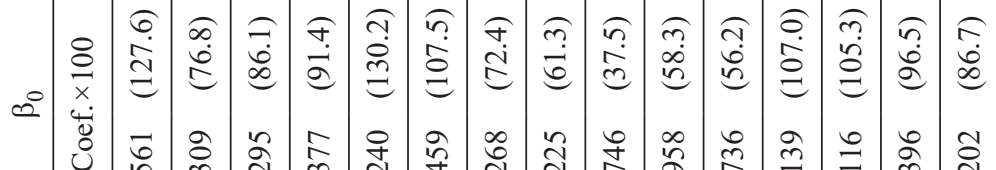

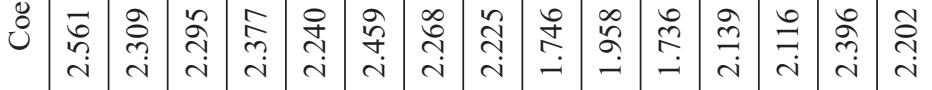

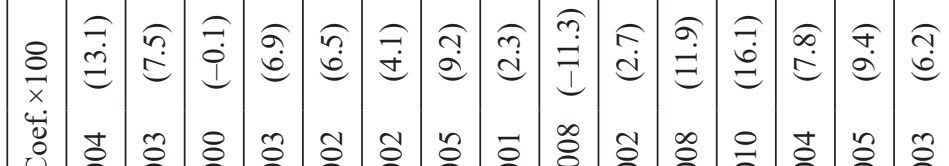

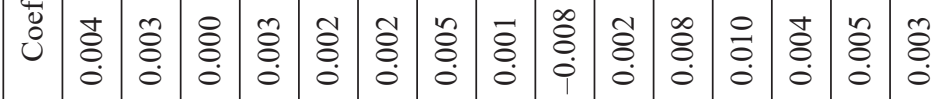

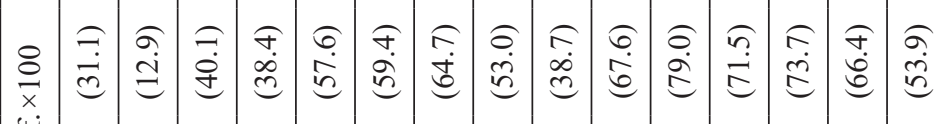

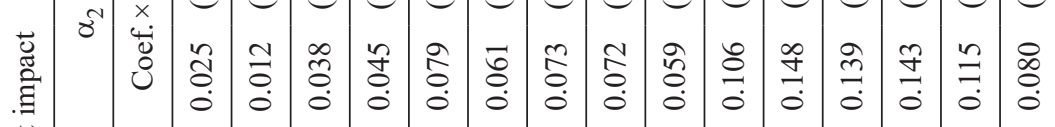

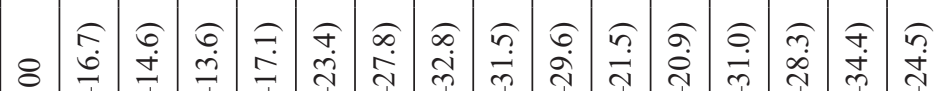

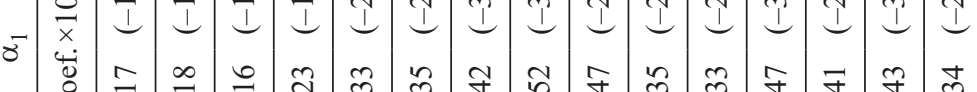

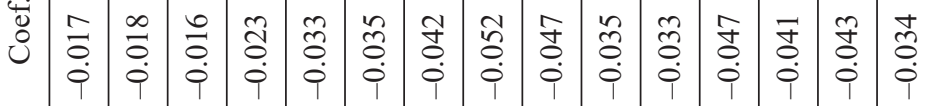

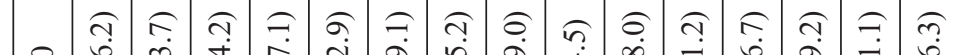

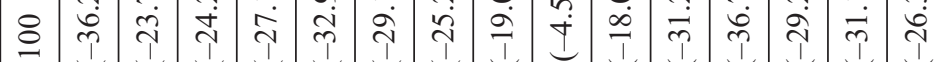

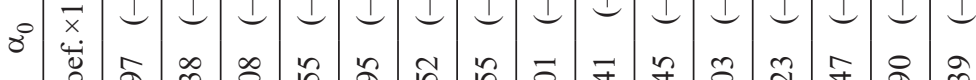

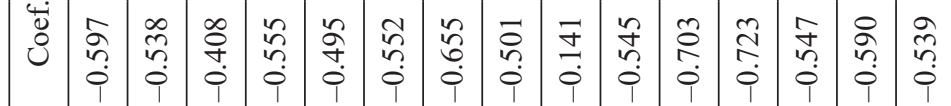

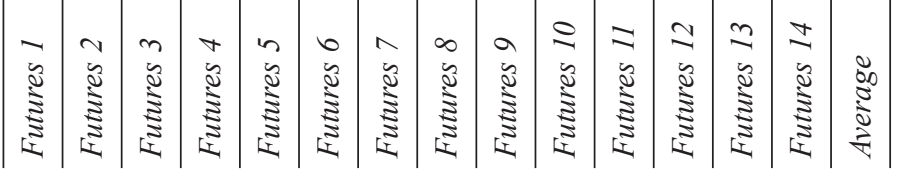




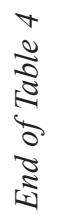

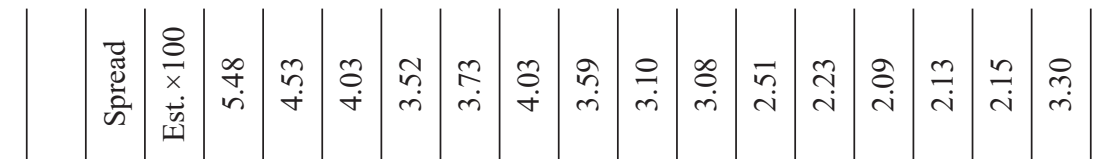

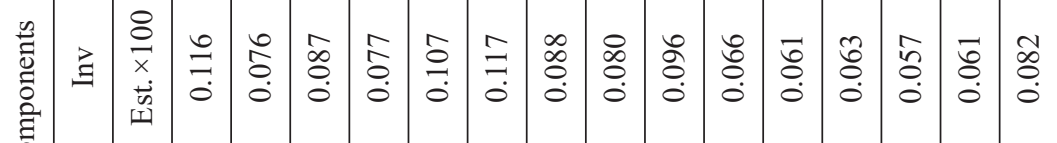

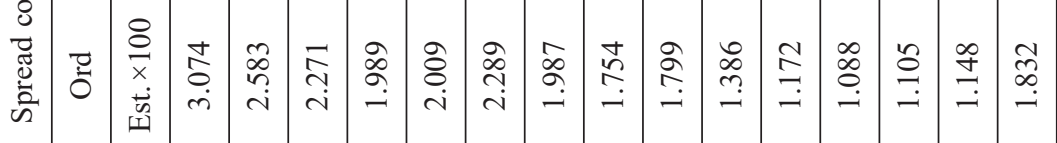

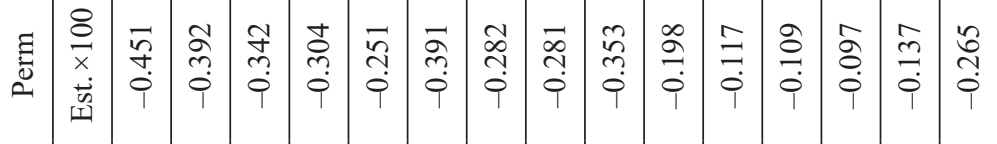

$$
\begin{aligned}
& \text { əิ) }
\end{aligned}
$$

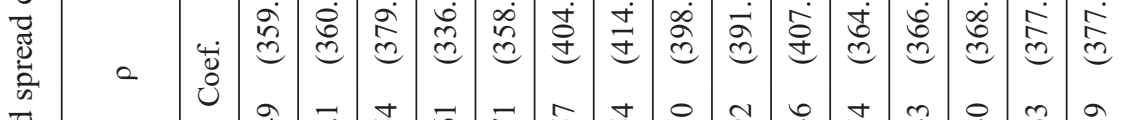

$$
\begin{aligned}
& \text { 흘 }
\end{aligned}
$$

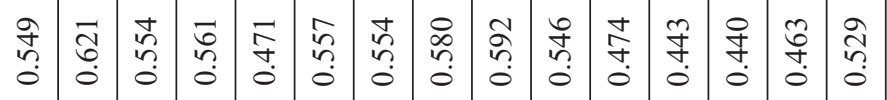

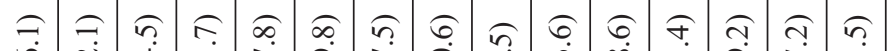

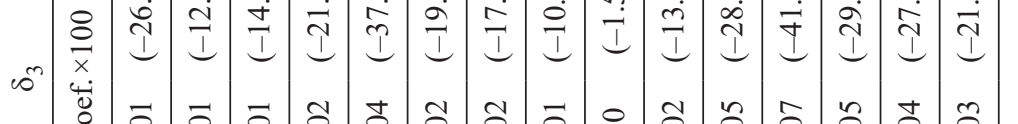

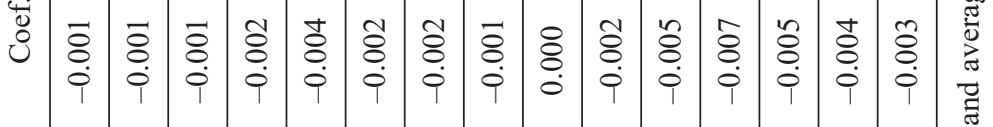

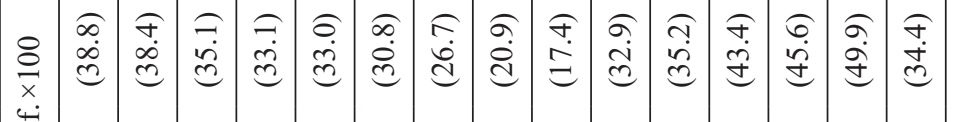

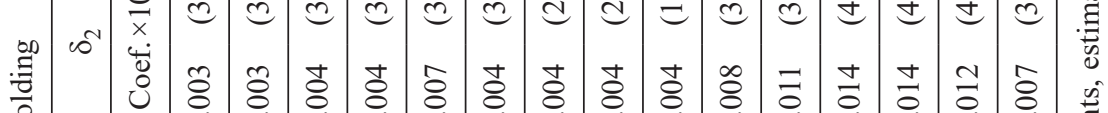

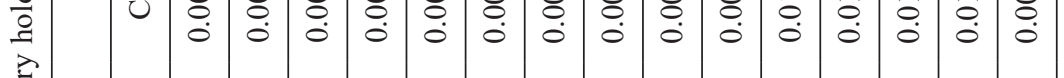

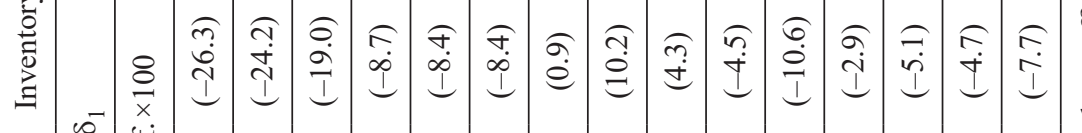

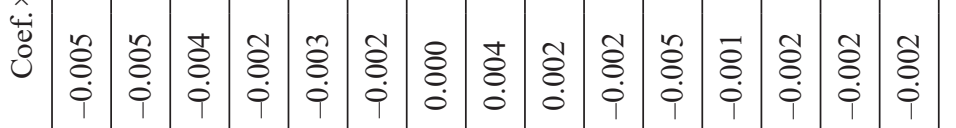

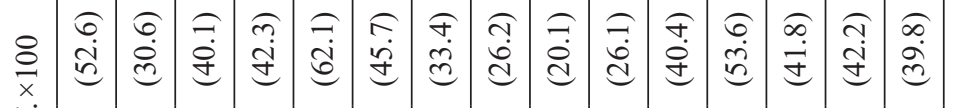

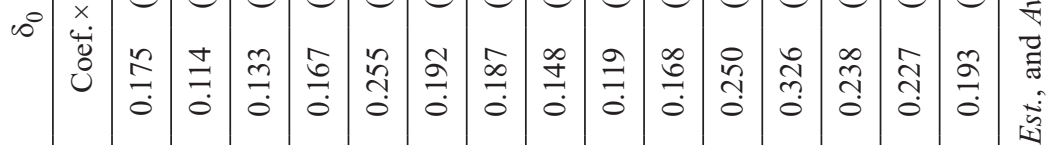

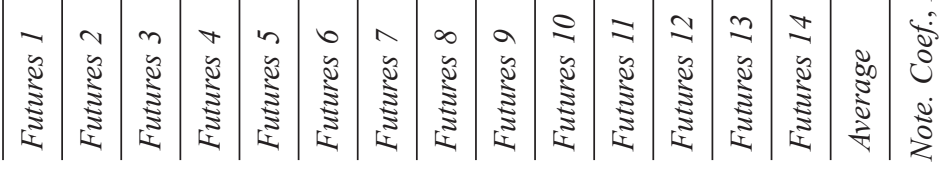

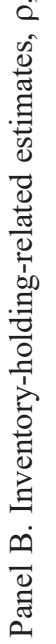


The $\beta_{2}$ estimates are highly significant and negative in all futures series, which reflects the economies of scale for the order processing costs. Submitting larger orders causes the temporary transaction cost per unit size to decrease. The highly significant and positive $\delta_{2}$ estimates imply that the inventory holding cost tends to increase as investors submit larger orders. This is quite plausible in that the inventory levels of liquidity suppliers fluctuate considerably after they submit large buy or sell orders. Consequently, submitting large orders increases their inventory holding costs. The negative $\delta_{3}$ estimates imply that the inventory holding cost decreases with market liquidity. This reflects that liquidity suppliers feel less burden with regard to managing their inventory levels when the liquidity is relatively abundant, because they can buy or sell the assets more easily than when they face illiquid market conditions.

\section{Information effect of duration and size on the inventory holding component}

This section examines how order duration and size, the two most important variables that futures traders decide when the traders implement their intraday trading strategies, ${ }^{10}$ affect the information content of the inventory holding component. We analyze the relationship between the information content and various futures market variables in a regression framework. Specifically, for each one-hour-long intraday interval, we estimate the extended model and measure the futures market variables to carry out the pooling regression.

The information effect of order duration (size) on the inventory holding component is measured as Info $D=\mid\left[\delta_{0}+\delta_{1} \ln \left(D^{L}\right)+\delta_{2} \sqrt{\bar{S}}+\delta_{3} \bar{L}\right]-\left[\delta_{0}+\delta_{1} \ln \left(D^{H}\right)+\delta_{2} \sqrt{\bar{S}}+\right.$ $\left.\delta_{3} \bar{L}\right] \mid\left(\operatorname{Info} O^{S}=\left|\left[\delta_{0}+\delta_{1} \ln (\bar{D})+\delta_{2} \sqrt{S^{L}}+\delta_{3} \bar{L}\right]-\left[\delta_{0}+\delta_{1} \ln (\bar{D})+\delta_{2} \sqrt{S^{H}}+\delta_{3} \bar{L}\right]\right|\right)$, where $D^{L}\left(S^{L}\right)$ and $D^{H}\left(S^{H}\right)$ denote the $10^{\text {th }}$ and $90^{\text {th }}$ percentile values of the order duration (size) in each interval, respectively. The number of total observations becomes 5,178 for each measure. We regress $\operatorname{Info}{ }^{D}$ or $\operatorname{Info}{ }^{S}$ on the futures market variables observed in each interval, as follows.

$$
\begin{aligned}
& \text { Info }_{i}{ }^{m}=\gamma_{0}+\gamma_{1} \text { Duration }_{i}+r_{2} \text { Size }_{i}+r_{3} \text { Liquidity }_{i}+r_{4} \text { Price }_{i}+ \\
& \gamma_{5} \text { Volatility }_{i}+r_{6} \text { TTM }_{i}+\gamma_{7} \text { Intra }_{i}+e_{i},
\end{aligned}
$$

where $m$ becomes $D(S)$ when analyzing the duration (size) effect, and $i$ denotes the $i^{\text {th }}$ intraday interval. The independent variables are Duration, Size, Liquidity, Price,

\footnotetext{
${ }^{10}$ Informed and/or professional investors choose the size and speed of their orders when they implement their strategic order transactions. They can submit large orders or smaller orders (i.e., the choice of order sizes). They can also increase the speed of trading by fragmenting their trades within a short time period, or decrease the speed to reduce the market impact or for any other strategic reasons. This is related to the choice of order duration. If they decide to trade, there are no other tools for implementing the strategic transaction except adjusting the size and speed of orders. That is why previous studies, including Chung et al. (2016), emphasize that order duration and size are the two most important variables that futures traders choose based on their trading strategies.
} 
and Volatility, which denote the average $\log$ order duration $(\ln (\bar{D}))$, square root of the average order size $(\sqrt{\bar{S}})$, square root of the average market depth $(\sqrt{\bar{L}})$, average futures transaction price, and realized volatility calculated from five-minute log returns, respectively. TTM and Intra are time to maturity and intraday dummy variables, which are incorporated to control the maturity effect (Chang, Lin 2015) and intraday variations (Garvey, Wu 2014), respectively.

Table 5 reports the estimation results of regression Equation (11) by setting the dependent variable as $\operatorname{Info} o^{D}$ or $\operatorname{Info} o^{S}$. According to the $t$-statistics shown in the parentheses, most of the futures market variables are significantly related to the two information measures, Info $D$ and Info $S$. The estimated coefficients of order duration are significantly positive and those of order size are significantly negative, which indicates that the higher order aggressiveness (i.e., shorter duration and larger size) decreases the explanatory powers of duration and size on the inventory holding component. This is quite plausible because the prevalence of the fast and aggressive trading represented by short durations and large orders implies that futures traders concentrate less on their inventory levels and more on short-term profit making, informed trading, and other trading motives.

Table 5. Regression analyses

\begin{tabular}{|c|c|c|c|c|}
\hline \multirow[b]{2}{*}{ Constant } & \multicolumn{2}{|c|}{$\operatorname{Info} o^{D}$} & \multicolumn{2}{|c|}{$\operatorname{Info} o^{S}$} \\
\hline & $-1.20 \mathrm{E}-03$ & $(-2.26)$ & $1.39 \mathrm{E}-04$ & $(2.36)$ \\
\hline Duration & $3.70 \mathrm{E}-03$ & $(36.86)$ & $2.00 \mathrm{E}-04$ & $(17.93)$ \\
\hline Size & $-1.31 \mathrm{E}-03$ & $(-8.61)$ & $-1.09 \mathrm{E}-04$ & $(-6.46)$ \\
\hline Liquidity & $3.12 \mathrm{E}-05$ & $(4.92)$ & $-4.68 \mathrm{E}-06$ & $(-6.65)$ \\
\hline Price & $9.11 \mathrm{E}-06$ & $(5.97)$ & $3.75 \mathrm{E}-06$ & $(22.10)$ \\
\hline Volatility & 3.266 & $(3.14)$ & 0.646 & $(5.60)$ \\
\hline$T T M$ & $3.79 \mathrm{E}-06$ & $(2.30)$ & $-6.03 \mathrm{E}-07$ & $(-3.29)$ \\
\hline Intra & $-6.83 \mathrm{E}-05$ & $(-3.74)$ & $-4.91 \mathrm{E}-06$ & $(-2.43)$ \\
\hline Adjusted- $R^{2}$ & \multicolumn{2}{|c|}{0.246} & \multicolumn{2}{|c|}{0.379} \\
\hline
\end{tabular}

The coefficients of liquidity have different signs depending on whether we analyze the information effect of duration or size, which is plausible in that longer duration implies decreased market liquidity whereas larger size implies increased liquidity. The liquidity coefficient is positive for the duration effect, whereas it becomes negative for the size effect, which indicates that abundant liquidity increases (decreases) the additional explanatory powers of order duration (size) on the information content of the inventory holding component.

The volatility and price have consistent effects on the information content of the inventory holding component both for order duration and size. The coefficients of both volatility and price are positive, which implies that the information effects of order duration and size increase when the market is volatile and the futures price is increasing. 
The negative coefficients of intraday dummy variables reflect the intraday pattern of inventory holding costs imposed on liquidity suppliers. Around the daily closing period of each trading day, liquidity suppliers such as day traders tend to trade in a hurry, and do not carry the inventory during the overnight period and reduce their inventory holding costs. In other words, during the afternoon trading period of each trading day, the inventory holding cost issues dominate other trading motives, and the additional effects of duration and size on the information content of the inventory holding component become relatively small.

\section{Conclusions}

This study contributes to the existing literature by suggesting a microstructure model that incorporates various microstructure variables and exploits rich market information, thus providing economic implications to intraday traders. We construct the comprehensive order indicator model by considering the order duration, order size, market liquidity, and inventory holding costs. Analyzing the highly liquid KOSPI200 futures market dataset, we find that not only do the order duration and size have significant information content on the intraday price dynamics, but the inventory holding cost of liquidity suppliers also explains a significant portion of model-implied spreads, indicating the important role of liquidity suppliers that previous studies have ignored. We also find that the information effects of order duration and size on the inventory holding component are explained by various market characteristics, namely the trading environment, asset price, liquidity level, volatility, and intraday time periods.

Our framework is quite flexible and significantly improves the existing microstructure models that have serious shortcomings due to the restrictive assumptions, such as the unit order size, same inter-transaction time, disregarding the liquidity environment, and absence of implicit liquidity suppliers. The estimation results of our models provide economic implications to day traders, professional investors, and/or market practitioners who have to use various types of microstructure information to implement effective intraday investment and order submission strategies on observed trade sizes, order durations, current market liquidity, and their inventory holding levels.

Our structural model and the conclusion obtained through the analysis of the liquid market dataset encourage the employment and application of order indicator models, which have been stagnant in the market microstructure field. The incorporation of the inventory holding component into our framework is motivated by the existence of limit order traders who play the important role of liquidity suppliers, and thus can be sensitive to the explicit and implicit inventory holding costs. We show that our model has various economic implications in a highly liquid emerging derivatives market. Future research may apply this model to an illiquid market where the degree of market liquidity and inventory holding costs reflect the more serious consideration of market participants who implement intraday strategies. 


\section{Acknowledgement}

The authors are grateful for the helpful comments and suggestions from Izolda Joksiene, Lars Nordén, and Robert I. Webb. This work was supported by the National Research Foundation of Korea Grant funded by the Korean Government (NRF2014S1A5B8060964).

\section{References}

Ahn, H-.J.; Cai, J.; Hamao, Y.; Ho, R. 2002. The components of the bid-ask spread in a limit-order market: evidence from the Tokyo Stock Exchange, Journal of Empirical Finance 9: 399-430. https://doi.org/10.1016/S0927-5398(02)00003-8

Ahn, H-.J.; Kang, J.; Ryu, D. 2008. Informed trading in the index option market: the case of KOSPI 200 options, Journal of Futures Markets 28: 1118-1146. https://doi.org/10.1002/fut.20369

Ahn, H-.J.; Kang, J.; Ryu, D. 2010. Information effects of trade size and trade direction: evidence from the KOSPI 200 index options market, Asia-Pacific Journal of Financial Studies 39: 301-339. https://doi.org/10.1111/j.2041-6156.2010.01016.x

Angelidis, T.; Benos, A. 2009. The components of the bid-ask spread: the case of the Athens stock exchange, European Financial Management 15: 112-144.

https://doi.org/10.1111/j.1468-036X.2007.00416.x

Biais, B.; Glosten, L.; Spatt, C. 2005. Market microstructure: a survey of microfoundations, empirical results, and policy implications, Journal of Financial Markets 8(2): 217-264.

https://doi.org/10.1016/j.finmar.2004.11.001

Chang, C.; Lin, E. 2015. Cash-futures basis and the impact of market maturity, informed trading, and expiration effects, International Review of Economics and Finance 35: 197-213.

https://doi.org/10.1016/j.iref.2014.09.003

Chen, T.; Li, J.; Cai, J. 2008. Information content of inter-trade time on the Chinese market, Emerging Markets Review 9: 174-193. https://doi.org/10.1016/j.ememar.2008.02.006

Choi, J. Y.; Salandro, D.; Shastri, K. 1988. On the estimation of bid-ask spreads: theory and evidence, Journal of Financial and Quantitative Analysis 23(2): 219-230.

https://doi.org/10.2307/2330882

Chung, K. H.; Park, S. G.; Ryu, D. 2016. Trade duration, informed trading, and option moneyness, International Review of Economics and Finance 44: 395-411.

https://doi.org/10.1016/j.iref.2016.02.003

Easley, D.; O'Hara, M. 1987. Price, trade size, and information in securities markets, Journal of Financial Economics 19: 69-90. https://doi.org/10.1016/0304-405X(87)90029-8

Furfine, C. 2007. When is inter-transaction time informative?, Journal of Empirical Finance 14: 310-332. https://doi.org/10.1016/j.jempfin.2006.06.002

Garvey, R.; Wu, F. 2014. Clustering of intraday order-sizes by uninformed versus informed traders, Journal of Banking and Finance 41: 222-235. https://doi.org/10.1016/j.jbankfin.2014.01.026

Glosten L. R.; Harris, L. 1988. Estimating the components of the bid-ask spread, Journal of Financial Economics 21: 123-142. https://doi.org/10.1016/0304-405X(88)90034-7

Glosten, L. R.; Milgrom, P. R. 1985. Bid, ask and transaction prices in a specialist market with heterogeneously informed traders, Journal of Financial Economics 14(1): 71-100.

https://doi.org/10.1016/0304-405X(85)90044-3

Grammig, J.; Theissen, E.; Wünsche, O. 2011. Time and price impact of a trade: a structural approach. Working paper. Universities of Tübingen and Mannheim. 
Hagströmer, B.; Henricsson, R.; Nordén, L. 2016. Components of the bid-ask spread and variance: a unified approach, Journal of Futures Markets 36(6): 545-563.

https://doi.org/10.1002/fut.21776

Han, C.; Hwang, S.; Ryu, D. 2015. Market overreaction and investment strategies, Applied Economics 47(54): 5868-5885. https://doi.org/10.1080/00036846.2015.1058913

Huang, R. D.; Stoll, H. R. 1997. The components of the bid-ask spread: a general approach, Review of Financial Studies 10: 995-1034. https://doi.org/10.1093/rfs/10.4.995

Kim, H.; Ryu, D. 2012. Which trader's order-splitting strategy is effective? The case of an index options market, Applied Economics Letters 19(17): 1683-1692.

https://doi.org/10.1080/13504851.2012.665590

Kim, J. S.; Ryu, D. 2015. Effect of the subprime mortgage crisis on a leading emerging market, Investment Analysts Journal 44(1): 20-42.

Kim, J. S.; Ryu, D.; Seo, S. W. 2015. Corporate vulnerability index as a fear gauge? Exploring the contagion effect between U.S. and Korean markets, Journal of Derivatives 23(1): 73-88. https://doi.org/10.3905/jod.2015.23.1.073

Kyle, A. S. 1985. Continuous auctions and insider trading, Econometrica 53: 1315-1335. https://doi.org/10.2307/1913210

Lee, J.; Kang, J.; Ryu, D. 2015. Common deviation and regime-dependent dynamics in the index derivatives markets, Pacific-Basin Finance Journal 33: 1-22.

https://doi.org/10.1016/j.pacfin.2015.02.001

Lee, J.; Ryu, D. 2016. Asymmetric mispricing and regime-dependent dynamics in futures and options markets, Asian Economic Journal 30(1): 47-65. https://doi.org/10.1111/asej.12084

Liu, C.; Maheu, J. M. 2012. Intraday dynamics of volatility and duration: evidence from Chinese stocks, Pacific-Basin Finance Journal 20: 329-348. https://doi.org/10.1016/j.pacfin.2011.11.001

Madhavan, A. 2000. Market microstructure: a survey, Journal of Financial Markets 3(3): 205258. https://doi.org/10.1016/S1386-4181(00)00007-0

Madhavan, A.; Richardson, M.; Roomans, M. 1997. Why do security prices change? A transaction-level analysis of NYSE stocks, Review of Financial Studies 10: 1035-1064.

https://doi.org/10.1093/rfs/10.4.1035

Roll, R. 1984. A simple implicit measure of the effective bid-ask spread in an efficient market, Journal of Finance 39(4): 1127-1139. https://doi.org/10.1111/j.1540-6261.1984.tb03897.x

Ryu, D. 2011. Intraday price formation and bid-ask spread components: a new approach using a cross-market model, Journal of Futures Markets 31: 1142-1169.

https://doi.org/10.1002/fut.20533

Ryu, D. 2012. The effectiveness of the order-splitting strategy: an analysis of unique data, Applied Economics Letters 19(6): 541-549. https://doi.org/10.1080/13504851.2011.587764

Ryu, D. 2013a. Price impact asymmetry of futures trades: trade direction and trade size, Emerging Markets Review 14: 110-130. https://doi.org/10.1016/j.ememar.2012.11.005

Ryu, D. 2013b. Spread and depth adjustment process: an analysis of high-quality microstructure data, Applied Economics Letters 20(16): 1506-1510.

https://doi.org/10.1080/13504851.2013.828401

Ryu, D. 2015a. The information content of trades: an analysis of KOSPI 200 index derivatives, Journal of Futures Markets 35(3): 201-221. https://doi.org/10.1002/fut.21637

Ryu, D. 2015b. Information content of inter-transaction time: a structural approach, Journal of Business Economics and Management 16: 697-711.

https://doi.org/10.3846/16111699.2013.804873 
Ryu, D. 2016. Considering all microstructure effects: the extension of a trade indicator model, Economics Letters 146: 107-110. https://doi.org/10.1016/j.econlet.2016.07.025

Ryu, D.; Kang, J.; Suh, S. 2015. Implied pricing kernels: an alternative approach for option valuation, Journal of Futures Markets 35(2): 127-147. https://doi.org/10.1002/fut.21618

Ryu, D.; Yang, H. 2017. Price disagreements and adjustments in index derivatives markets, Economics Letters 151: 104-106. https://doi.org/10.1016/j.econlet.2016.12.016

Sim, M.; Ryu, D.; Yang, H. 2016. Tests on the monotonicity properties of KOSPI 200 options prices, Journal of Futures Markets 36(7): 625-646. https://doi.org/10.1002/fut.21763

Song, W.; Ryu, D.; Webb R. I. 2016. Overseas market shocks and VKOSPI dynamics: a Markovswitching approach, Finance Research Letters 16: 275-282.

https://doi.org/10.1016/j.frl.2015.12.007

Spierdijk, L. 2004. An empirical analysis of the role of the trading intensity in information dissemination on the NYSE, Journal of Empirical Finance 11: 163-184.

https://doi.org/10.1016/j.jempfin.2002.12.004

Stoll, H. R. 1989. Inferring the components of the bid-ask spread: theory and empirical tests, Journal of Finance 44(1): 115-134. https://doi.org/10.1111/j.1540-6261.1989.tb02407.x

$\mathrm{Xu}, \mathrm{X}$. E.; Chen, P.; Wu, C. 2006. Time and dynamic volume-volatility relation, Journal Banking \& Finance 30: 1535-1558. https://doi.org/10.1016/j.jbankfin.2005.05.011

Yang, H.; Choi, H. S.; Ryu, D. 2016. Option market characteristics and price monotonicity violations, Journal of Futures Markets 37(5) (in press). https://doi.org/10.1002/fut.21826

Webb, R. I.; Ryu, D.; Ryu, D.; Han, J. 2017. The price impact of futures trades and their intraday seasonality, Emerging Markets Review 26: 80-98. https://doi.org/10.1016/j.ememar.2016.01.002

Doojin RYU is a tenured Associate Professor at the College of Economics, Sungkyunkwan University (SKKU). He is the Editor of Investment Analysts Journal (SSCI) and the Associate Editor of Emerging Markets Review (SSCI). He has published articles in high-quality journals, including Journal of Business Ethics, Journal of Banking \& Finance, Economics Letters, International Review of Economics \& Finance, Journal of Futures Markets, Finance Research Letters, Journal of Derivatives, and Physica $A$. He has published about 60 papers in SSCI-listed journals. 